\title{
Spawning and Movements of Smallmouth Bass (Micropterus \\ Dolomieui) in the Mid-Columbia River
}
J. C. Montgomery
D. H. Fickeisen

November 1978

Prepared for the U.S. Department of Energy under Contract EY-76-C-06-1830

Pacific Northwest Laboratory Operated for the U.S. Department of Energy by Battelle Memorial Institute 
NOTICE

This report was prepared as an account of work sponsored by the United States Covernment. Neither the United States nor the Department of Energy, nor any of their employees, nor any of their contractors, subcontractors, or their employees, makes any warranty, express or implied, or assumes any legal liability or responsibility for the accuracy, completeness or usefulness of any information, apparatus, product or process disclosed, or represents that its use would not infringe privately owned rights.

The views, opinions and conclusions contained in this report are those of the contractor and do not necessarily represent those of the United States Government or the United States Department of Energy.

\author{
PACIFIC NORTHWEST LABORATORY \\ operated by \\ BATTELLLE \\ for the \\ UNITED STATES DEPARTMENT OF ENERGY \\ Under Contract EY-76-C-06-1830
}
Printed in the United States of America Available from
National Technical information Service United States Department of Commerce 5285 Port Royal Road
Springfield, Virginia 22151

Price: Printed Copys : Microfiche $\$ 3.00$

NTIS

- Pages Selling Price

$\begin{array}{ll}001-025 & \$ 4.00 \\ 026-050 & \$ 4.50 \\ 051-075 & \$ 5.25 \\ 076-100 & \$ 6.00 \\ 101-125 & \$ 6.50 \\ 126-150 & \$ 7.25 \\ 151-175 & \$ 8.00 \\ 176-200 & \$ 9.00 \\ 201-225 & \$ 9.25 \\ 226-250 & \$ 9.50 \\ 251-275 & \$ 10.75 \\ 276-300 & \$ 11.00\end{array}$


SPAWNING AND MOVEMENTS OF SMALLMOUTH BASS

(Micropterus dolomieui) IN THE MID-COLUMBIA

RIVER
J. C. Montgomery
D. H. Fickeisen

November 1978

Prepared for

the U.S. Department of Energy

under Contract EY-76-C-06-1830

Pacific Northwest Laboratory

Richland, WA 99352 
SPAWNING AND MOVEMENT OF

SMALLMOUTH BASS (Micropterus dolomieui)

IN THE MID-COLUMBIA RIVER

\section{ABSTRACT}

Forty radio frequency and 120 standard type Floy ${ }^{\circledR}$ tags were attached to smallmouth bass to monitor their movements in connection with Columbia River water level fluctuations. Tagging information provided data on bass movement during and after their spawning period as well as their location and habitat preference. Field data indicated spawning occurred from April through June with bass leaving backwater areas and returning to the main stem of the Columbia River in August 1976 and late June 1977. River movement appeared to be related to water depth, current and available forage. Radio-tagged fish were monitored a maximum of $61 \mathrm{~km}$ and $F$ loy ${ }^{\circledR}$ tags were returned by fishermen from as far as $63 \mathrm{~km}$.

Spawning success was estimated for White Bluffs, Hanford and $F$ Area sloughs during 1976 and 1977 and appeared to be related to water level fluctuations. Loss of bass because of entrapment, predation, thermal or oxygen stress and desiccation was observed in several temporary ponds.

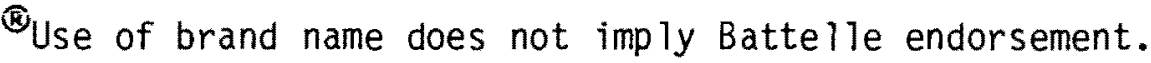




\section{SPAWNING AND MOVEMENT OF \\ SMALLMOUTH BASS (Micropterus dolomieui) \\ IN THE MID-COLUMBIA RIVER}

\section{INTRODUCTION}

Studies on smalimouth bass (Micropterus dolomieui) were conducted at Hanford by Pacific Northwest Laboratory as part of a continuing program to evaluate the effects of water level fluctuations on fishes and other aquatic biota. Water levels in the Columbia River are manipulated by hydro-electric dams that artificially regulate flow patterns to meet power peaking and flood control demands. Preliminary observations in 1976 indicate juvenile and adult smallmouth bass were subject to losses from entrapment, desiccation and predation as a result of short-term water level fluctuations. Furthermore, bass nests were impacted by dehydration, siltation and abrupt temperature changes.

Bass typically spawn in the study areas in late spring and early summer, and water temperature is important in the timing of spawning and the rate of development of the eggs and larvae. Changes in water level can potentially effect reproductive success in several ways. Rising water levels may result in flushing the warmer backwater areas with cold water, delaying or halting egg development. Heavy currents can cover eggs with silt and could wash larvae out of the nest. Falling water levels may drive away the guarding male bass, resulting in predation and poor water circulation in the nest. During severe water level fluctuations, the nest can be exposed to the air and become desiccated. After the young leave the nest they may continue to be subjected to the effects of fluctuating water levels as they seek forage and cover in shallow water. Here they may become entrapped in small ponds or stranded by receding river levels.

During 1976 and 1977, bass experienced two extremely different water flow regimes. High water conditions existed in the spring and summer of 1976 and water levels did not recede to usual summer flows until late September. Low water conditions occurred in 1977 with less fluctuating water levels. The Columbia River seldom reached normal seasonal flow patterns between March and 
October. Different water level patterns presented specific problems for small mouth bass during and after their spawning period. Both years provided data under contrasting water flow regimes.

This report summarizes findings on bass resident time in study sites, length of spawning activity, movements of bass during and after spawning, entrapment and desiccation of bass, and an estimate of spawning success during 1976 and 1977.

\section{METHODS}

Spawning and behavior of smallmouth bass were observed and monitored from March to mid-October in 1976 and 1977 in White Bluffs, F Area and Hanford sloughs (Figure 1). Bass movements were monitored in the river between Priest Rapids Dam and Pasco, Washington. Observations consisted of walking surveys and sampling of bass populations with an electro-fisher, seine net and hook and line gear. Crayfish traps, trapnets and electro-fishing were used to evaluate forage species available to entrapped bass. General observations provided information on bass spawning behavior and allowed semiquantitative estimates of abundance of bass fry in the three study sites. Sampling provided data on timing of adult bass presence within each study area as we 11 as specimens for tagging with radio transmitters and Floy ${ }^{\circledR}$ tags (Figure 2 ). Mortalities of fry and entrapped bass were estimated from visual sightings and bass collections counted from several entrapment areas. Bass losses from stranding, dehydration, or predation were estimated by counting actual mortalities observed.

Seven adult bass were tagged in 1976 and in 1977 forty adult bass were tagged with radiotelemetry tags to gather information on spawning behavior, entrapment and desiccation. One hundred and twenty additional bass were tagged with standard $F$ loy ${ }^{\circledR}$ tags to supplement the radiotelemetry data. Radio frequency transmitter tags and receivers were fabricated by the Bioelectronics Laboratory at the University of Minnesota (Tester and Siniff, 1976). The receivers operated with a frequency of 53.000 to $53.999 \mathrm{MHz}$ and were capable of distinguishing 100 different crystal-tuned radio tags. Each transmitter 


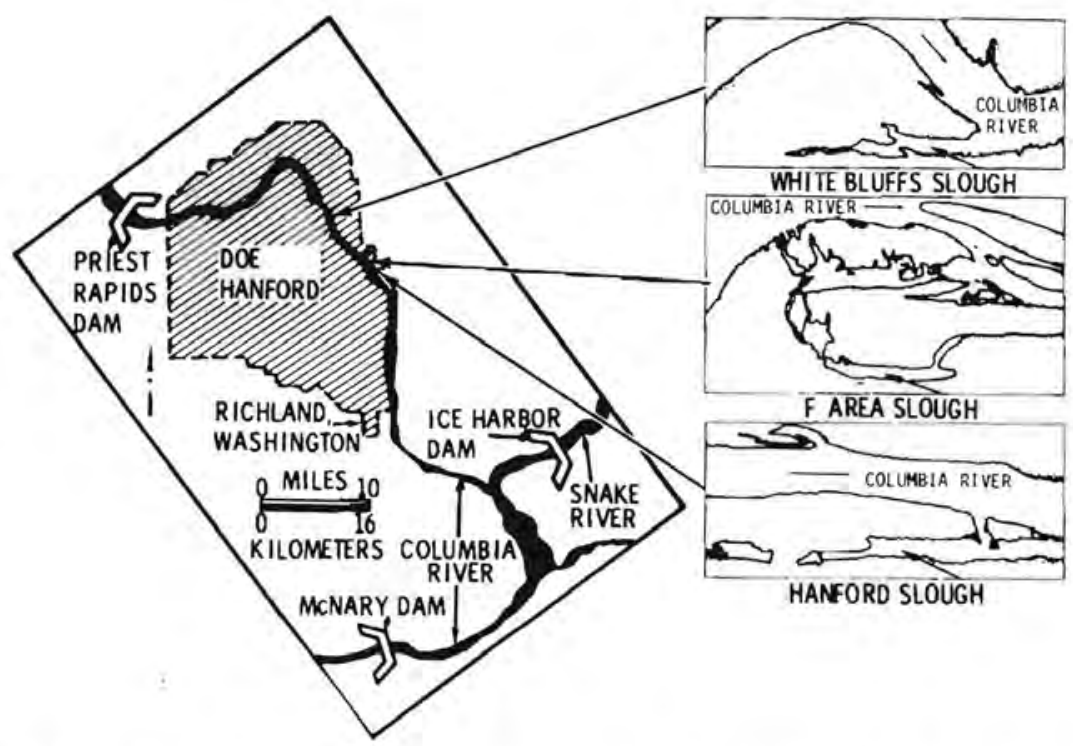

FIGURE 1. Area map showing specific locations of three study areas.

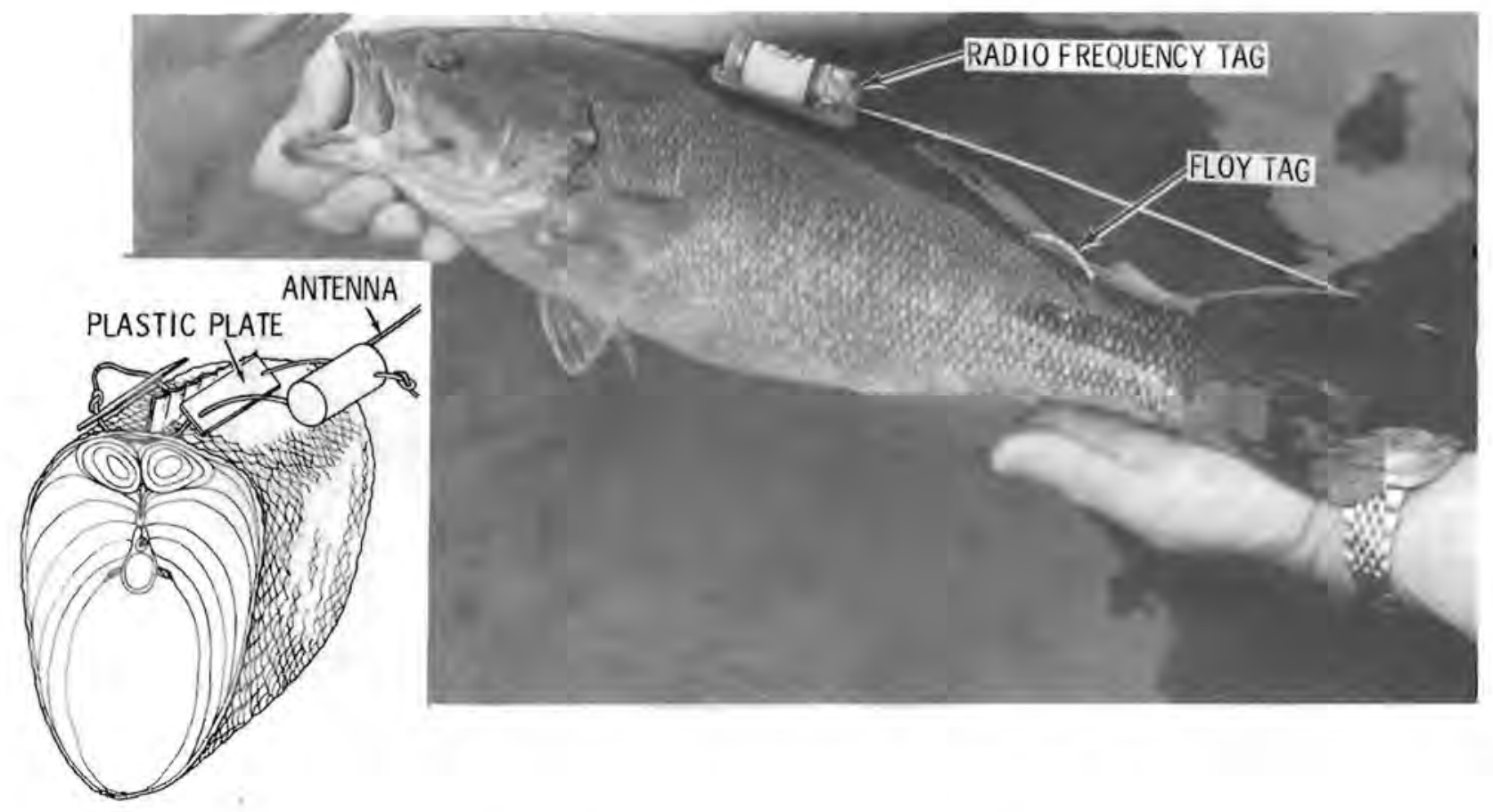

FIGURE 2. Smallmouth bass displaying both radio frequency and Floy tags which were normally attached to separate fish. Inset: Cross section showing radio tag attachment. 
was encased in epoxy, which also anchored the teflon-coated attachment cables. Radio tags measured $50.8 \mathrm{~mm} \times 15 \mathrm{~mm}$ and had a dry weight of $19.3 \pm 0.5 \mathrm{~g}$. Length of the plastic coated wire antenna measured $30.1 \mathrm{~mm} \pm 4$.

Radio tags were attached by inserting the attachment cable with a surgical needle slightly below the fishes dorsal fin (Figure 2 inset). The cable was passed through a small flexible plastic plate on each side of the fish. These

plates allowed the transmitter to be firmly attached to the fish. Floy ${ }^{\circledR}$ tags were attached below the posterior end of the dorsal fin (Figure 2). All incisions from tagging and capture abrasions were treated with malachite green to retard infection. Before release, standard length, general condition, sex (if possible) and estimated weight of the fish were recorded.

After release, radio-tagged adult bass were monitored by antennas mounted on a truck (Figure 3 ) and boat. Radio-tagged bass were monitored two or more times week ly and their locations recorded on a river map. Since signal strength decreases with swimming depth, signal attenuation was used to semiquantitatively evaluate depth of individual fish. Signal attenuation was calibrated by lowering several radio-tags to various water depths and determining signal strength. Battery life of radiotelemetry tags averaged $4.0 \mathrm{mo}+0.5$.

\section{RESULTS}

\section{Spawning Data}

Adult smallmouth bass began frequenting the study sites in mid-March and remained in the areas until August. Male bass guarded nests until late July; gravid females were collected until mid-August. However, no nesting or guarding activity was observed after July. Radiotelemetry tagging of seven bass at one study site (White Bluffs slough) demonstrated the feasibility of tracking these fish and provided information on post spawning movement. Bass location data indicated that the majority of spawning adults did not return to the river until late August.

Field observations indicated a poor success for bass spawning in 1976. Eggs failed to hatch in several bass nets at the three study sites and 
relatively few fry were observed. Five bass nests were located and observed at White Bluffs Slough from the time of egg incubation until sac fry left the nesting sites. Of the five nests, only two displayed hatching success and less than 50 swim-up fry were observed. A typical smallmouth bass nest should produce approximately 2000 fry (Scott and Crossman, 1973).

\section{Spawning Data}

Area bass began inhabiting White Bluffs and Hanford Sloughs in mid-March and F Area Slough in early April. Spawning activity began in April and continued into July. Several adult bass remained in the study areas until late July. F Area Slough received high water in early April for a short period, (2-6 days) which permitted mature spawning bass to enter the area. The water receded, and the bass were entrapped in the slough. These adult bass have remained confined since mid-Apri1, 1977, and cannot return to the river until

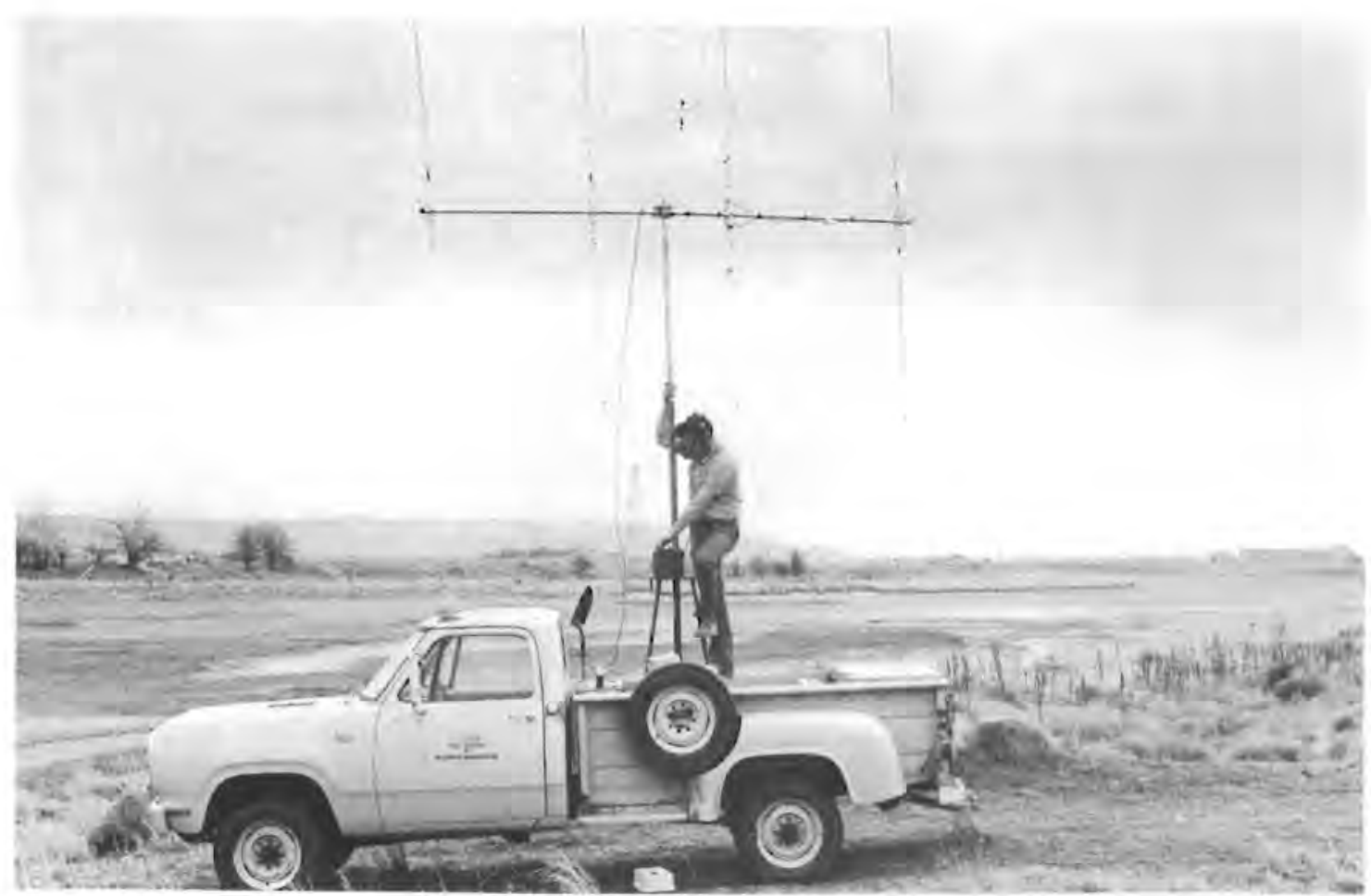

FIGURE 3. Truck with mounted receiving antenna. 
high water flows permit their departure. Smallmouth bass spawning in 1977 appeared successful at the three study sites. Bass entrapped at F Area Slough apparently had the best reproductive success with observed swim-up fry estimated at 30,000 to 40,000 fish.* Bass spawning at White Bluffs and Hanford Slough appeared less successful. An estimated 10,000 to 15,000 bass fry were observed at each site.

Tagging Data

Radiotelemetry tagging of 40 bass provided information on the location of individual fish from late March to mid-October, 1977. Adult bass with the average standard length of $37.19 \pm 2.47 \mathrm{~cm}$, were fitted with transmitters in White Bluffs (15 fish), F Area (15) and Hanford Slough (10). Data from these movements quantified residence time in study areas and identified bass locations after fish returned to the river. Spawning activity of radio-tagged adults began in late April and the peak egg hatch was complete by mid-June. However, several tagged fish remained in the sloughs until July. All mature fish monitored in F Area Slough remained entrapped throughout the battery life of the tags. Floy ${ }^{\circledR}$ tags were attached to several other bass and subsequent recapture data supported entrapment time, and river movement information.

Upon leaving the spawning areas, radio-tagged bass remained near the mouth of White Bluffs and Hanford Sloughs for 1 to 2 weeks. Bass at White Bluffs Slough remained in the river pool adjacent to the slough mouth and tended to move to deeper water $(6-16.5 \mathrm{~m})$. Radio-tagged smallmouth bass at Hanford Slough tended to disperse downstream. Typical tracks of radio-tagged fish are indicated in Figure 4. Radio-tagged bass moved a maximum of $61 \mathrm{~km}$ downstream (Table 1). Dispersed Hanford Slough bass stayed near mid-stream islands, shorelines and in backwater areas directly connected to the Columbia River. Floy ${ }^{\circledR}$ tags from Hanford Slough fish were returned by fishermen from as far as $63 \mathrm{~km}$ downstream and supported movement patterns indicated by radio tag location data. All tags returned were from bass captured in the Columbia River.

\footnotetext{
*Estimates of Swim-up fry resulted from observations of bass fry "pods" sighted at White Bluffs, F Area, and Hanford Sloughs $(80+$ pods). Each "pod" appeared to conta in 500 to 2,000 fry.
} 
HANFORD SLOUGH

TAG 750

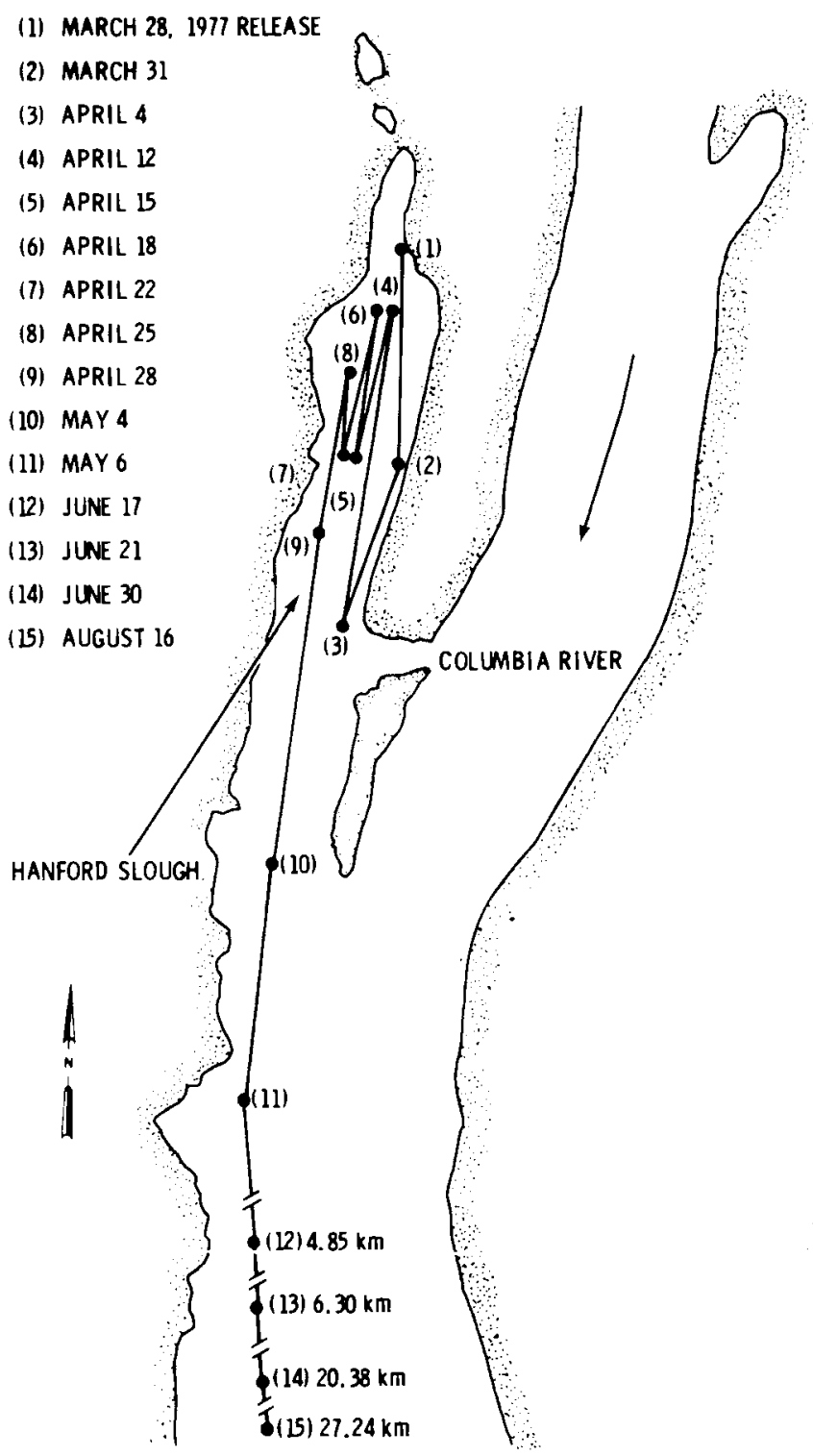

WHITE BLUFFS

TAG 250

\begin{abstract}
(1) MARCH 31, 1977 RELEASE
\end{abstract}
(2) APRIL 1

(3) MAY 9

(4) MAY 12

(5) MAY 20

(6) MAY 26

(7) JUNE 10

(8) JUNE 17

(9) June 21

(10) June 30
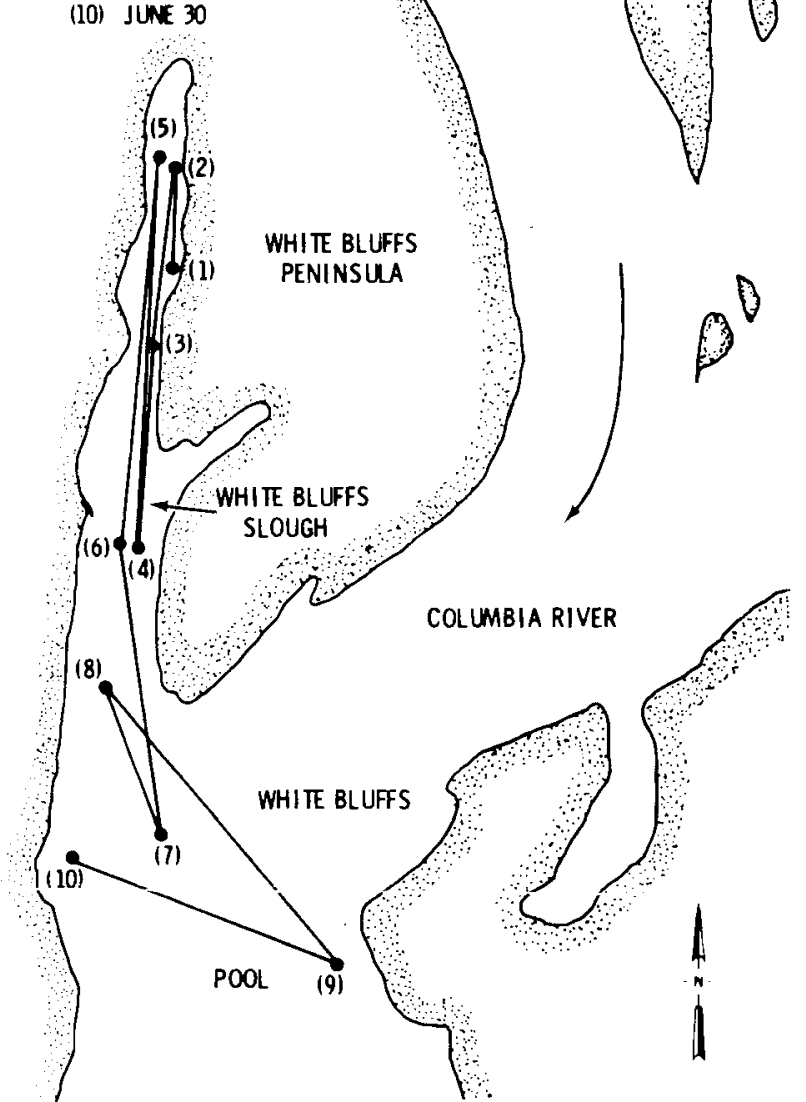

FIGURE 4. Representative bass movement for Hanford and White Bluffs Sloughs. 
TABLE 1

Maximum Movement by Individually Tagged Bass

Monitored from April Through September

WHITE BLUFFS SLOUGH

Tag Frequency Kilometers Moved

$\begin{array}{ll}070 & 1.11 \\ 130 & 1.48 \\ 150 & 1.30 \\ 170 & 1.67 \\ 210 & 1.48 \\ 230 & 1.30 \\ 250 & 1.85 \\ 290 & 1.30 \\ 310 & 1.30 \\ 390 & 1.48 \\ 430 & 0.93^{\mathrm{a}} \\ 510 & 1.48 \\ 570 & 5.74 \\ 690 & 1.67 \\ 790 & 1.67 \\ & \text { Excluding \#430 } \\ & \text { Mean =1.77 } \\ & \text { Var(Mean) }= \\ & 0.10 \\ & \text { SE }=0.31\end{array}$

HANFORD SLOUGH

Tag Frequency Kilometers Moved

$\begin{array}{cc}030 & 7.78 \\ 050 & 11.12 \\ 590 & 0.93^{\mathrm{b}} \\ 610 & 61.00 \\ 750 & 27.24 \\ 890 & 7.60 \\ 910 & 1.30 \\ 930 & 2.41 \\ 950 & 9.45 \\ 990 & 7.60\end{array}$

\footnotetext{
a Fish became entrapped May 12, 1977 until the tag failed on September 6, 1977.

b Tag failed after 11 days of operation.
} 


\section{Entrapment and Desiccation}

During 1976 and 1977, entrapment and subsequent losses of bass by desiccation, predation, or thermal stress were found in several different ponds and flooded areas. At F Area Slough in 1976, a creek about $2.6 \mathrm{~km}$ long was created by water entering the north end of the peninsula and flowing southward into the study slough. Several temporary ponds were created in the creek and yearling smallmouth bass were later observed trapped and desiccated in the ponds. At the extreme north end of F Area, the creek formed a large pond approximately $100 \times 800 \mathrm{~m}$ with a maximum depth of $2.3 \mathrm{~m}$. About 150 to 250 adult and juvenile smallmouth bass were observed in this pond. The fish eventually died from terrestrial predators and desiccation when the pond dried in early October 1976.

Another pond at F Area Slough about $2 \mathrm{~m}$ deep, contained in September 1976, about 80 to 100 yearling smallmouth and largemouth bass (Micropterus salmoides). These fish were lost when the pond dried in late July 1977. A third pond about $0.35 \mathrm{~m}$ deep near the north end of $F$ Area entrapped an estimated 80 yearling largemouth and smallmouth bass. These fish died during the winter due to freezing and terrestrial predators.

At the south end of $F$ Area Slough, the main channel turns eastward and a high bank, which normally functions as an effective dike, forms a slack water area approximately $400 \times 200$ meters. In 1976, several bass nests within the slack water area produced an estimated 200 to 300 smallmouth fry. However, shortly after the bass fry moved to shoreline cover, the water level increased and flooded a recessed grassy area directly behind the bank. During high flows, water enters through two lower portions in the bank creating about 125 to 150 ponds of various sizes. Smallmouth bass fry were observed dispersing throughout the flooded grassy area. Receding water isolated the ponds and they dried within 24 hours. On the next day, only six bass fry were observed in the slack water area.

During 1976, Columbia River water levels remained higher than normal until late September. One large pond (440 m $\times 100 \mathrm{~m} \times 4 \mathrm{~m}$ deep) at the north end of Hanford Slough became separated from the main slough. It was estimated that 
the pond contained about 100 to 200 adult smallmouth and largemouth bass. This pond remained isolated until April 1978. Evaporation of water reduced it to approximately one quarter of its original size. During this 18 month entrapment period, several collections of adult bass were made. Sampling indicated the number of available forage organisms were rapidly reduced. Fish condition factors declined and malnutrition was reflected in the entrapped population. By March 1978, intensive sampling produced no bass.

\section{$\underline{\text { DISCUSSION }}$}

The 45-day postnesting period is important to successful smallmouth production in Iowa streams (Cleary, 1956). When air temperatures dropped from 23.9 to $11.1^{\circ} \mathrm{C}$ and remained for 10 days, bass abandoned their nests. Eggs became infested with fungi and lost their adhesiveness. An increase in water level swept dead eggs from the nest. Surber (1943) found smallmouth bass nests were seldom located where there was any perceptible current. Henderson and Foster (1956) reported that cold water flushing through the study sites after spawning apparently prevented hatching.

Smallmouth bass spawning success at Hanford appears related to the extent of water level fluctuation that occurs within spawning areas. Poor spawning success observed in 1976 was likely caused when cold water and heavy currents swept through the spawning sites, creating abrupt temperature changes and siltation. Receding water levels returned the eggs to higher temperatures. Repetition of this situation occurred several times during the egg incubation period.

During 1976, flows that flooded the slough areas resulted in colder water temperatures, which could explain the extended adult bass residence time and late spawning at the three study sites. Male smallmouth bass were guarding nests until mid-July and gravid females were collected as late as mid-August. In contrast, spawning in 1977 appeared successful for smallmouth bass. Moreover, minimal river water level fluctuations appear to account for the successful hatch and survival of fry. F Area Slough, where no water fluctuations occurred during or after spawning in the slough itself, contained the largest number of swim-up fry. 
Habitat preference (Munther, 1970), availability of prey, and river current appear to account for differences in adult bass movement following spawning. White Bluff's pool offers a suitable habitat for bass foraging and recovery from spawning activity. The pool contains large numbers of food fishes and crayfish and has a large portion of slack or back eddy deep water. Radiotagging data indicate that White Bluff's bass prefer to recover from spawning activity in deeper portions of the river and this pool provided the fish these depths in slack water. However, Hanford Slough fish do not have this option. The river directly below the mouth of the Slough is swift flowing and does not extend to as great a depth as at White Bluff's pool. About $3.2-3.8 \mathrm{~km}$ below Hanford Slough, slack water and greater depths can be found, and a few tagged bass traveled to and remained in this area. However, several of the monitored fish dispersed further downstream. Floy ${ }^{\circledR}$ tags returned by fishermen supported radio tag location data, and several tags were returned from areas where radiotagged fish had been or were still present.

Entrapment and subsequent mortalities apparently resulting from desiccation, thermal stress, malnutrition or predation occurred in 1976 and 1977 on adult, juvenile, and 0 -age smallmouth bass. Swim-up bass fry appear especially vulnerable to fluctuating water. The "black fry" disperse among aquatic plants near shore shortly after they emerge from the nest and tend to move into the grassy cover as water levels rise. When the water recedes, many fry are trapped and subsequently lost. Such water fluctuations typically occur over a 24-hr period and it is likely a large portion of each year's bass hatch is lost in this manner. We suspect that these are density-independent mortalities and that they may be reflected in recruitment to the adult population and year class strength.

Longer term entrapment ponds lasting 1-18 mo were found to contain several hundred adult, yearling smallmouth and largemouth bass at $F$ Area (excluding main study slough), Hanford and White Bluffs sloughs. The majority of these fish were eventually lost to desiccation, thermal stress, malnutrition and/or predation. 
F Area adult bass became entrapped in the main slough in April 1977. These fish would be unable to return to the Columbia River until high water permits. However, when the water begins to rise in the spring, the sexually mature bass may remain in the slough to complete spawning. The fish may move back to the Columbia River if 1978 water levels are high enough to permit fish passage.

\section{Future Studies}

Preliminary studies on smallmouth bass in the Hanford section of the Columbia River indicated several areas requiring additional field and laboratory research to provide information needed to effectively protect bass populations. An expanded program should be developed to investigate the following research areas for smallmouth bass:

- Determine the effects of water current, siltation and temperature fluctuations on development and mortality of bass eggs.

- Ascertain whether or not spawning adult bass migrate to the same spawning sites each year, and the relationship between number of returning adult spawners and new recruits.

- Determine the importance to regional bass populations of the Hanford area spawning sites, and if other significant spawning areas are available in the region.

- Further define typical adult bass movement patterns, and determine if separate genetic populations (races or stocks) of smallmouth bass exists in this region.

- Examine bass spawning success in relation to water level fluctuation.

- Determine the effect of chronic malnutrition on bass reproductive success. 


\section{REFERENCES}

Cleary, R. E. 1956. Observations on factors affecting smallmouth bass production in Iowa. Tour Wildlife Management, 20(4): 353-359.

Henderson, C. and R. F. Foster. 1956. Studies of smallmouth bass (Micropterus dolomieu) in the Columbia River near Richland, Washington. Trans. Amer. Fish. Soc. 36: 112-127.

Munther, G. L. 1970. Movement and distribution of smallmouth bass in the middle Snake River. Trans. Amer. Fish. Soc. 99(1): 44-53.

Scott, W. B. and E. J. Crossman. 1973. Freshwater fishes of Canada. Bullet in 184, Fisheries Research Board of Canada, Ottawa, p. 730.

Surber, E. W. 1943. Observations on natural and artificial propagation of smallmouth black bass, Micropterus dolomeiu. Trans. Amer. Fish. Soc. 72: $233-245$.

Tester, J. R. and D. B. Siniff. 1976. Vertebrate Behavior and Ecology. Progress Report for period July 1, 1975 through June 30, 1976 CDO-1332 123. Prepared for U.S. Energy Research and Development Administration. Contract No. E (11-1)-1332 by University of Minnesota, Minneapolis, 63 pp. 


\section{ACKNOWLEDGMENTS}

The authors would like to thank D. W. Crass for his diligence in following radio-tagged bass and recording their movements and C. D. Becker, J. A. Strand and T. L. Page for reviewing the manuscript. 


\section{DISTRIBUTION}

No. of

Copies

\section{DFFSITE}

1 A. A. Churm

D.0.E. Chicago Patent Group 9800 South Cass Avenue

Argonne, IL 60439

27 Technical Information Center

5 D. H. Hamilton, Jr. D.O.E. Office of Health and Environmental Research

Washington, DC

R. Watters

D.O.E. Office of Health and Environmenta 1 Research

Washington, DC

R. A. Lewis

D.O.E. Office of Health and Environmenta 1 Research

Washington, DC

J. D. Liverman

D.O.E. Office of Health and Environmental Research

Washington, DC

J. Swinebroad

D.O.E. Office of Health and

Environmental Research

Washington, DC

Cliff Millenback (5)

Washington State Department of Game

600 North Capital Way

01 ympia, WA

Merril Spence

Washington State Department of

Game

209 Maringold

Ephrata, WA
No. of

Copies

James McColgin

Washington State Department of Game

658 West First

Kennewick, W'A

William Zook

Washington State Department of Game

209 Maringold

Ephrata, WA

Louis Lund

Washington State Dept. of Game 2802 Fruitvale Blvd.

Yakima, WA

ONSITE

5 D.O.E. Richland Operations Office

0. J. Elgert

H. E. Ransom

M. W. Tiernan

J. D. White

J. A. Zillich

62 Pacific Northwest Laboratory

C. D. Becker

B. W. Compton (4)

D. W. Crass

C. E. Cushing

C. L. Gibson

D. H. Fickeisen (2)

R. F. Foster

R. H. Gray

J. C.. Montaomery (10)

T. L. Page

W. H. Rickard

J. A. Strand 
PNL-2785

UC-97e

No. of

Copies

Pacific Northwest Laboratory (contd)

W. L. Templeton

B. E. Vaughan (2)

D. G. Watson

R. E. Wildung

Technical Information (5)

Publishing Coordination (2)

Freshwater Sciences (25) 